\title{
Erratum to: Unemployment and willingness to accept job offers: results of a factorial survey experiment
}

\author{
Martin Abraham ${ }^{1}$ Katrin Auspurg ${ }^{2}$ - Sebastian Bähr ${ }^{3} \cdot$ Corinna Frodermann $^{3}$ - Stefanie Gundert E $^{3}$ \\ Thomas Hinz ${ }^{4}$
}

\section{Erratum to:}

J Labour Market Res. (2013) 46:283-305

DOI 10.1007/s12651-013-0142-1

In the original publication the last two answer scales depicted in Fig. 1 had both left and right endpoints labelled as "Very unlikely". It should read "Very likely" at the right endpoints of the scales.

We apologise for this oversight.
If you accepted the offered job, your net household income will rise to 3,510 euros. The working hours are approximately 20 hours per week, and the job requirements are significantly below your professional skills. The job offers many opportunities for internal promotion and is limited to 3 years. The one-way trip from your current place of residence to the location of the job is approximately $\mathbf{6}$ hours. The labour market at the new location is worse than at your current residence. Finding appropriate housing there will require considerable effort.

a) How attractive is the job offer to you?

Very unattractive $\bigcirc \circ \bigcirc \circ \circ \circ \bigcirc \bigcirc \circ \circ \bigcirc$ Very attractive

b) How likely would you be to accept the offer?

Very unlikely $\bigcirc \circ \bigcirc \bigcirc \bigcirc \bigcirc \bigcirc \bigcirc \bigcirc \bigcirc \bigcirc$ Very likely

c) How likely would you be to completely move to the new location?

Very unlikely $\bigcirc \bigcirc \circ \bigcirc \bigcirc \bigcirc \bigcirc 0 \bigcirc \bigcirc \bigcirc$ Very likely

Fig. 1 Vignette Example (English translation, varied dimensions highlighted)

The online version of the original article can be found under doi: 10.1007/s12651-013-0142-1

Sebastian Bähr

sebastian.baehr@iab.de

1 University Erlangen-Nuremberg, Nuremberg, Germany

2 Ludwig-Maximilians-University, Munich, Germany

3 Institute for Employment Research (IAB), Nuremberg, Germany

4 University of Konstanz, Konstanz, Germany 